\title{
DESENVOLVIMENTO SUSTENTÁVEL NA CAATINGA É POSSÍVEL? VISÃO DOS ALUNOS DE ENSINO MÉDIO DE UMA ESCOLA PÚBLICA DE QUIXELÔ (CE)
}

\author{
Paula Guedes Vicente ${ }^{1}$ \\ Môngolla Keyla Freitas de Abreu$^{2}$ \\ Diego Coelho do Nascimento ${ }^{3}$ \\ Bruno Edson-Chaves ${ }^{4}$
}

Resumo: $\mathrm{O}$ artigo discute sobre a percepção de estudantes do Ensino Médio de uma escola pública do município de Quixelô, Ceará, Brasil, acerca das características, da conservação e do desenvolvimento sustentável na Caatinga. Metodologicamente, utilizamos o questionário para a coleta de dados, a análise de conteúdo e nuvem de palavras para a análise qualitativa, e apresentamos os dados quantitativos analisados através de tabelas e gráficos. Os resultados demonstram que apesar dos estudantes conhecerem o conceito "desenvolvimento sustentável", e sobre as características gerais da Caatinga, não conseguem desenvolver práticas sustentáveis para a convivência com o semiárido e/ou para mitigar os impactos já ocasionados neste bioma.

Palavras-chave: Biodiversidade; Sustentabilidade; Semiárido; Educação.

Abstract: The article discusses the perception of high school students from a public school in the city of Quixelô, Ceará, Brazil, about the characteristics, conservation and sustainable development in the Caatinga. Methodologically, we used the questionnaire for data collection, content analysis and word cloud for qualitative analysis, and presented the quantitative data analyzed through tables and graphs. The results demonstrate that although students know about the concept of sustainable development, and about the general characteristics of the Caatinga, they are unable to develop sustainable practices for living with the semiarid and / or to mitigate the impacts already caused in this biome.

Keywords: Biodiversity; Sustainability; Semiarid; Education.

\footnotetext{
${ }^{1}$ Instituto Federal de Educação, Ciências e Tecnologia do Ceará. E-mail: paulaguedesvicentep@gmail.com. Link para o Lattes: http://lattes.cnpq.br/1007080884984313

2 Secretaria de Educação do Estado do Ceará. E-mail: mongolla.abreu@prof.ce.gov.br Link para o Lattes: http://lattes.cnpq.br/6312317032247087

3 Universidade Federal do Cariri. E-mail: diego.coelho@ufca.edu.br. Link para o Lattes: http://lattes.cnpq.br/3077939057334697

${ }_{4}$ Universidade Estadual do Ceará. E-mail: bruno.edson@uece.br. Link para o Lattes: http://lattes.cnpq.br/3869403766919153
} 


\section{Introdução}

A Caatinga é um ambiente extremamente vulnerável à degradação ambiental devido às pressões antrópicas, baixos níveis de precipitações e mudanças climáticas (RIBEIRO; LIMA, 2020). Contudo, vem ocorrendo um despertar dos diferentes setores da sociedade para a situação atual (VELLOSO; SAMPAIO; PAREYN, 2002). Neste sentido, com o intuito de proporcionar um novo olhar para este ambiente, torna-se fundamental a introdução de novos conceitos (CAMARGO, 2003), que possam auxiliar na compreensão da relação entre meio ambiente e desenvolvimento econômico (DUARTE et al., 2015).

Assim, o desenvolvimento sustentável surge como um modelo que possibilita conciliar a relação do homem com a natureza e as relações dos homens entre si (CAMARGO, 2003). Entretanto, necessita-se de uma educação transformadora, e isso é viabilizado pela escola, a qual desempenha um papel importante na busca pela formação de sujeitos ativos na sociedade (GADOTTI, 2012). Além disso, a escola mostra-se como um ambiente oportuno para trabalhos de Educação Ambiental e divulgação científica, de modo específico referente às escolas presentes no semiárido; estas devem promover ações que valorizem o aspecto social e uma conscientização ambiental do bioma (RIBEIRO; LIMA, 2020).

A escola se apresenta de forma diferenciada no meio urbano e rural; no entanto, é através da perspectiva da educação como um direito social que se espera a superação dessa dicotomia, respeitando a diversidade e os direitos da criança, jovem ou adulto (ARROYO; CALDART; MOLINA, 2011). Neste contexto, o trabalho buscou analisar a percepção de alunos do ensino médio de uma escola da rede pública estadual de ensino, em relação à temática do desenvolvimento sustentável na Caatinga. É importante destacar, que essa escola tem sede na zona urbana e um anexo na zona rural, apresentando, desta forma, experiências decorrentes da influência social destes dois ambientes.

\section{Percurso Metodológico}

A pesquisa é do tipo descritiva (PRODANOV, 2013), cujo procedimento metodológico utilizado foi o levantamento - Survey (GIL, 2010). A natureza da análise foi baseada na expressão de ideias qualitativas e quantitativas (SAMPIERI; CALLADO; LUCIO, 2013), ou seja, uma pesquisa de métodos mistos.

O estudo teve como lócus uma escola de ensino médio da rede pública, situada no município de Quixelô, região Centro-Sul do estado do Ceará, Brasil. A escola tem um total de 448 alunos, distribuídos entre a sede (zona urbana de Quixelô) e o anexo (comunidade rural Riacho do meio - zona rural do município). A unidade da zona urbana funciona nos turnos tarde e noite; contudo a unidade da comunidade rural funciona somente no turno noite. 
Participaram como sujeitos dessa pesquisa, estudantes das turmas de $1^{\circ}, 2^{\circ}$ e $3^{\circ}$ ano do ensino médio, da sede e do anexo escolar, tendo representação de $50 \%$ dos estudantes dos turnos tarde e noite da sede, e participação de $100 \%$ dos estudantes do turno noite do anexo. A amostragem da sede foi reduzida em decorrência do número de estudantes ser representativamente maior que da escola anexo, contando com uma seleção dos sujeitos para essa amostragem de forma aleatória (Tabela 1).

Tabela 1: Total de alunos abordado na pesquisa. Por turma, turno e localização da escola.

\begin{tabular}{lllllll}
\hline & \multicolumn{3}{c}{ Sede (Zona urbana) } & \multicolumn{3}{c}{ Anexo (Zona rural) } \\
\hline Turno & $1^{\circ}$ ano & $2^{\circ}$ ano & $3^{\circ}$ ano & $1^{\circ}$ ano & $2^{\circ}$ ano & $3^{\circ}$ ano \\
\hline Tarde & 30 & 31 & 26 & - & - & - \\
Noite & 08 & 15 & 17 & 25 & 11 & 19 \\
\hline
\end{tabular}

Fonte: Dados da pesquisa (2020).

Os dados foram coletados por meio de um questionário como sugerido por Prodanov (2013), contendo questões objetivas e subjetivas. Vale destacar que antes de iniciar as atividades de pesquisa foi entregue o Termo de Consentimento Livre Esclarecido aos responsáveis pelos alunos e aos próprios alunos; evidenciando que o presente trabalho buscou seguir os aspectos éticos e legais da pesquisa (GRAY, 2012).

Para a análise do questionário, as questões objetivas foram tabuladas no programa de computador Microsoft Excel $2013^{\circledR}$ e construídos gráficos e tabelas. As questões subjetivas foram analisadas qualitativamente com o auxílio do Microsoft Word $2013^{\circledR}$, através da análise de conteúdo de Bardin (2016) e a nuvem de palavras (CAMARGO; JUSTO, 2013). Para esta última análise, foi utilizada uma ferramenta online gratuita (wordcloud.com).

\section{Aspectos Gerais sobre a Caatinga}

A princípio os estudantes da escola pública em questão foram indagados sobre o conceito do bioma Caatinga. As respostas foram organizadas em 7 categorias: 1- Localização / bioma (25,65\% do total de alunos); 2 - Aspectos sobre a flora (22,75\%); 3 - Aspectos sobre o clima $(20,75 \%) ; 4$ - Aspectos sobre a fauna $(8,75 \%) ; 5$ - Aspectos físicos e naturais $(4,7 \%) ; 6$ - Impactos ambientais $(3,7 \%) ; 7$ - Conceito ligado ao sertão $(0,85 \%)$, sendo que $13 \%$ dos estudantes deixaram a questão em branco, e as categorias 6 e 7 não obtiveram representatividade para os alunos do anexo; totalizando assim 7 categorias para a sede e apenas 5 para o anexo.

As categorias com maior expressividade foram a flora, o clima e a localização/bioma. Além disso, os estudantes citaram os aspectos climáticos, fazendo referência às altas temperaturas, a escassez hídrica e a localização da Caatinga. Esse bioma ocupa boa parte do Nordeste brasileiro, além do norte do estado de Minas Gerais, situado na região Sudeste (SAMPAIO; COSTA, 2012). É preciso uma reconstrução da imagem do sertão brasileiro, pois a imagem da 
Caatinga sempre esteve relacionada às grandes secas e aos seus aspectos climáticos (MARENGO et al., 2011).

Das duas categorias a mais citada pelos alunos da sede, foi a que se refere aos impactos ambientais, com destaque para as queimadas, desmatamentos e os costumes sertanejos. Neste sentido, a mudança na fitofisionomia da Caatinga, é decorrente de ações antrópicas, tais como o desmatamento (EVANGELISTA, 2011) e a queimada (NUNES et al., 2009).

A fim de verificar o conhecimento dos alunos sobre as peculiaridades da Caatinga, indagamos sobre algumas destas características (Figura 1).
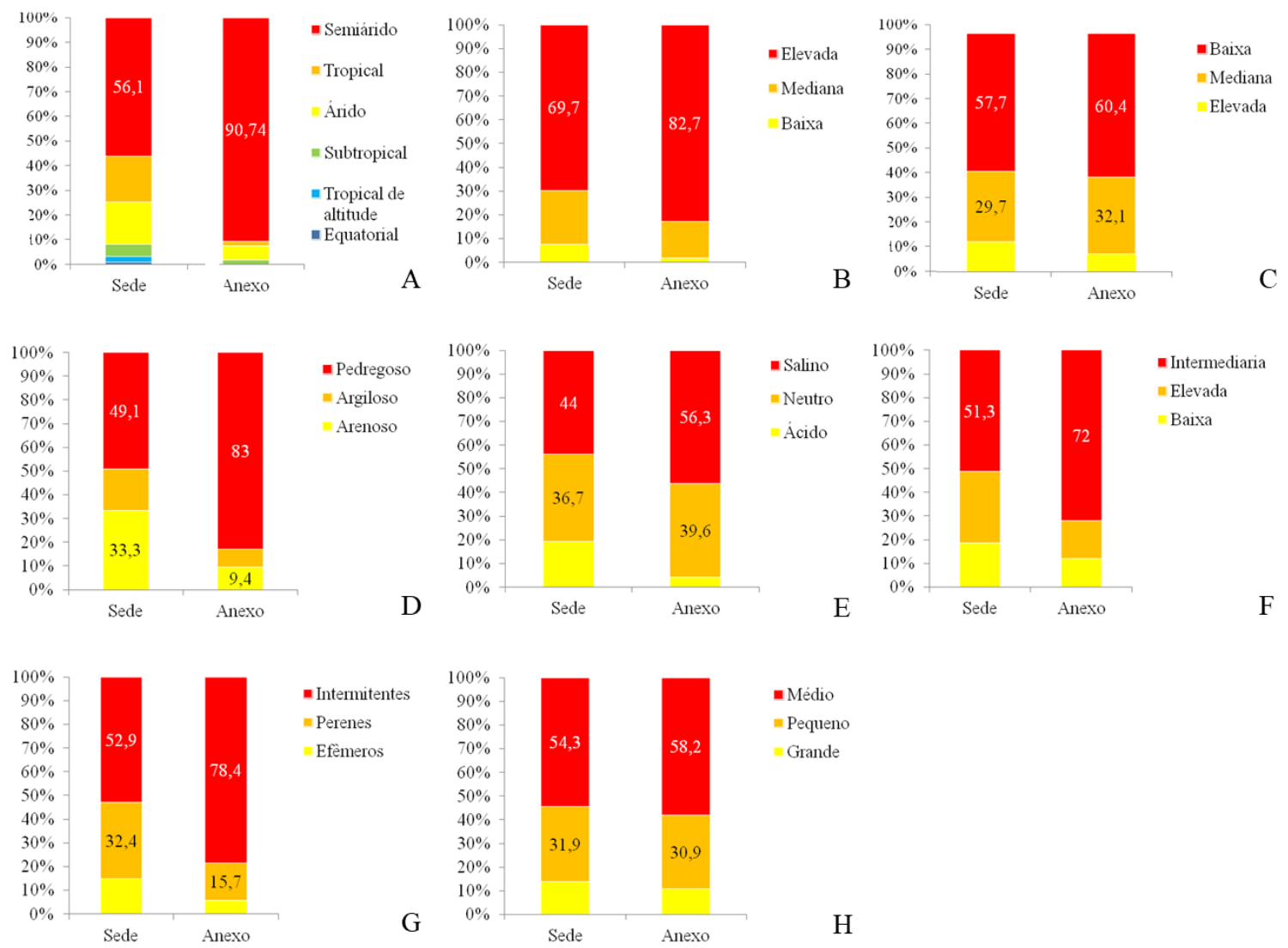

Figura 1: Respostas dos alunos a respeito das características físicas da Caatinga.

Fonte: Dados da pesquisa (2020).

Segundo a classificação de Koppen-Geiger, a mesma possui particularidades como altas temperaturas, baixa umidade relativa do ar, baixos índices de precipitação pluviométrica, o que possibilita aferir que este é semiárido (EMBRAPA, 2018).

Os estudantes afirmaram que o solo é predominantemente, pedregoso e salino, o que demonstra certo conhecimento sobre a pedologia da região. Uma vez que os solos da Caatinga formam um variado mosaico, em sua maior parte formado por um solo raso e pedregoso, embora apresente solo arenoso, 
que pode ser de alta ou baixa fertilidade (VELLOSO; SAMPAIO; PAREYN, 2002).

No que tange a hidrografia, a Caatinga é marcada por rios intermitentes. Esses refletem bem a influência da escassez de chuva na região, sendo exceção o rio São Francisco que apresenta um fluxo contínuo considerável. Contudo, os demais rios da região não são perenes. Essa condição natural climática semiárida, faz com que rios como, por exemplo, o Jaguaribe no Ceará, sofram tal influência e apresente regime intermitente em sua maior porção (ZANELLA; MARTINS, 2003).

Ainda sobre as características físicas da Caatinga, um fato marcante nos dados foi a expressividade das respostas dos alunos do anexo, sempre acima dos $50 \%$ para as características em questão. Tal fato pode associar-se ao fato destes morarem em áreas rurais, onde sempre tiveram um convívio com a natureza, e além disso os costumes e conhecimentos são passados ao longo das gerações, garantindo a disseminação destes saberes.

Além dos aspectos físicos do bioma, foi solicitado aos citados alunos a indicação de até três plantas e três animais do bioma, de forma a buscar entender seu conhecimento sobre a biodiversidade local (Figura 2).

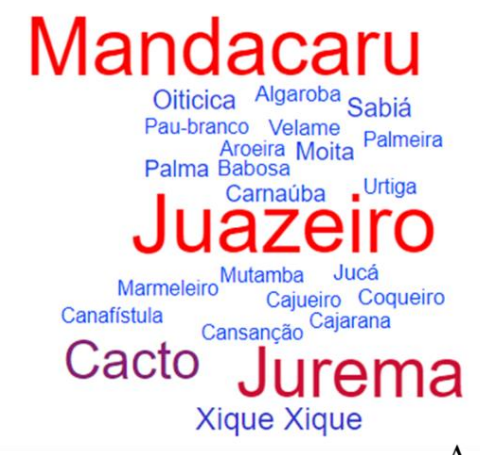

A

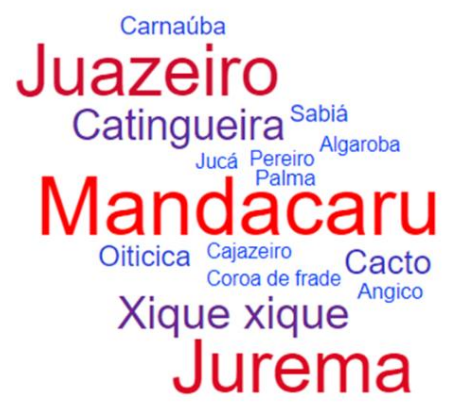

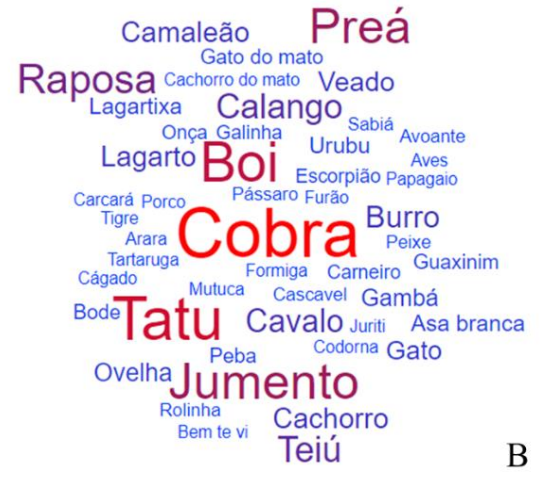

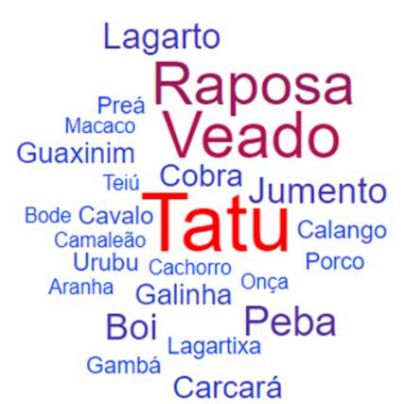

$\mathrm{D}$

Figura 2: Respostas dos alunos quando foram questionados sobre a diversidade da Flora (A e C) e Fauna ( $B$ e D) do Bioma Caatinga. A e B representam as respostas dos alunos da Sede, enquanto $C$ e $D$ dos estudantes do Anexo.

Fonte: Dados da pesquisa (2020). 
Os dados demonstram que no geral os alunos da sede relataram uma diversidade maior de plantas que os do anexo, o que é bastante curioso, pois, os estudantes da zona rural têm um maior contato com o ambiente natural. Contudo, tal resultado pode dar-se pelo fato do número de pessoas que responderam à pesquisa na sede ser bem maior que a quantidade de alunos do anexo. Entretanto, plantas como Mandacaru (Cereus jamacaru DC.), Jurema (Mimosa tenuiflora (Wild.) Poir.) e Juazeiro (Ziziphus joazeiro Mart.) obtiveram elevada representatividade para ambos os grupos de estudantes.

Ainda no aspecto florístico, observa-se que foram citadas poucas plantas exóticas, tais como Algaroba (Prosopis juliflora (Sw.) DC.), Babosa (Aloe vera (L.) Burm.f.) e Coqueiro (Cocos nucifera L.). Este aspecto deve ser destacado uma vez que espécies exóticas podem modificar a paisagem natural ameaçando a biodiversidade, pois, é do conhecimento geral que afetam o funcionamento do ecossistema e interferem bastante no espaço de plantas originárias da região (ZILLER, 2001). Dentre estas espécies, chama a atenção a Algaroba que é descrita como uma espécie invasora (OLIVEIRA; QUEIROZ, 2021), podendo gerar um grave problema ambiental, por alterar a composição e estrutura da vegetação (MORO et al., 2012).

Algumas espécies de plantas da Caatinga são empregadas na medicina popular, como: Angico (Anadenanthera colubrina (Vell) Brenan.), Imburana (Amburana cearenses Allemão.) e Aroeira-do-sertão (Myracrodruon urundeuva Allemão.) (CARDEL et al., 2014). Outras espécies apresentam potencial forrageiro, como: Mandacaru (C. jamacaru), Catingueira (Caesalpinia pyramidalis Tul.), Marmeleiro (Croton blanchetianus Baill.) e Juazeiro ( $Z$. joazeiro) (ARAÚJO et al., 2008).

Apesar de terem citado cerca de 30 plantas, sendo a maioria nativa, ainda é demonstrado um baixo conhecimento da flora da região dada a potencialidade da flora local, tendo espécies que servem para arborização, alimentação (Plantas Alimentares Não Convencionais - PANCs), recursos madeireiros e para artesanato, além de uma diversidade de plantas medicinais, aromáticas e tóxicas. O potencial florístico da Caatinga é bem amplo desde espécies herbáceas, arbusto e arbóreas;(,) todo esse potencial é amplamente utilizado pela população, principalmente para produção de medicamentos naturais, além de ser também um forte potencial forrageiro (PIMENTEL; GUERRA, 2009).

Apesar dos estudantes do anexo expressarem uma diversidade menor de plantas, neste grupo destacam-se o Xique-xique e a Catingueira. A utilização de tais plantas tem demonstrado ser uma excelente alternativa para a alimentação dos animais nos períodos mais secos, porém deve-se ter cuidado para que tal atividade não cause a extinção das mesmas (CAVALCANTI; RESENDE, 2004). Com isso, podemos atribuir às respostas dos alunos a relação com as atividades realizadas pela população rural em busca de subsistência e garantir a alimentação para os animais. 
Quanto ao aspecto faunístico (Figura 2), os dados demonstram que os alunos identificam uma diversidade maior que à flora, tanto os estudantes da sede quanto do anexo. Para Salatino e Buckeridge (2016) parece ser uma característica humana perceber mais os animais que as plantas na natureza; tal comportamento, de origem neurofisiológica e cultural, é caracterizado como cegueira botânica; além da presença de um forte zoocentrismo (exposição maior da mídia e do ensino aos organismos animais que vegetais).

Os alunos da zona urbana destacaram as seguintes indicações de animais: Cobra, Tatu, Boi (Bos taurus L. 1758), Jumento (Equus africanus asinus) e Preá (Cavia aperea Erxleben 1777); enquanto para a zona rural o destaque foi para: Tatu, Raposa e Veado. O bioma Caatinga possui uma diversidade de espécies da fauna, no entanto, poucas espécies de vertebrados são endêmicas desta região, pois estas não dispõem de estratégias para sobreviver ao período de seca; além disso, percebe-se uma forte ação dos caçadores (OLMOS; SILVA; ALBANO, 2005).

Dentre os grupos de animais citados, apenas quatro invertebrados (formiga, mutuca, aranha e escorpião), um peixe (de forma genérica), sete répteis, onze aves e vinte e dois mamíferos. Os estudos sobre os animais da Caatinga, infelizmente, ainda são insuficientes; contudo, sabe-se que temos uma ampla diversidade de espécies na fauna, como é o caso das aves (SILVA, et al., 2003) e mamíferos (OLIVEIRA; GONÇALVES; BONVICINO, 2003) com cerca de 510 e 143 espécies distribuídas em toda a extensão do bioma, respectivamente.

Embora, as pesquisas demonstrem uma quantidade significativa de aves na Caatinga, poucas foram citadas. Como os alunos da sede citaram uma quantidade maior de animais, consequentemente mencionaram mais aves. $O$ que pode ser reflexo direto da caça predatória na região e da perda de habitat destas espécies. Consequentemente, tais condições influenciam na resposta dos estudantes, tendo em vista que eles não percebem a presença constante de aves na região. Para Alves, Gonçalves e Vieira (2012) a caça é uma atividade bem tradicional na região, com importante papel econômico e diretamente vinculada a falta de conservação da Caatinga.

\section{Conservação da Biodiversidade da Caatinga}

A biodiversidade da Caatinga vem reduzindo gradualmente, especialmente devido ao uso inapropriado dos recursos naturais, sobretudo quando a população local utiliza estes para sua sobrevivência (ALVES; SILVA; VASCONCELOS, 2009).

Quando indagados sobre ações antrópicas na Caatinga, os alunos reafirmaram os impactos na preservação deste bioma (Figura $3 \mathrm{~A}$ ). A compreensão dos estudantes sobre as consequências negativas ocasionadas por ações humanas no bioma Caatinga reitera a necessidade de medidas que proporcionem avanços na relação do homem com a natureza. 

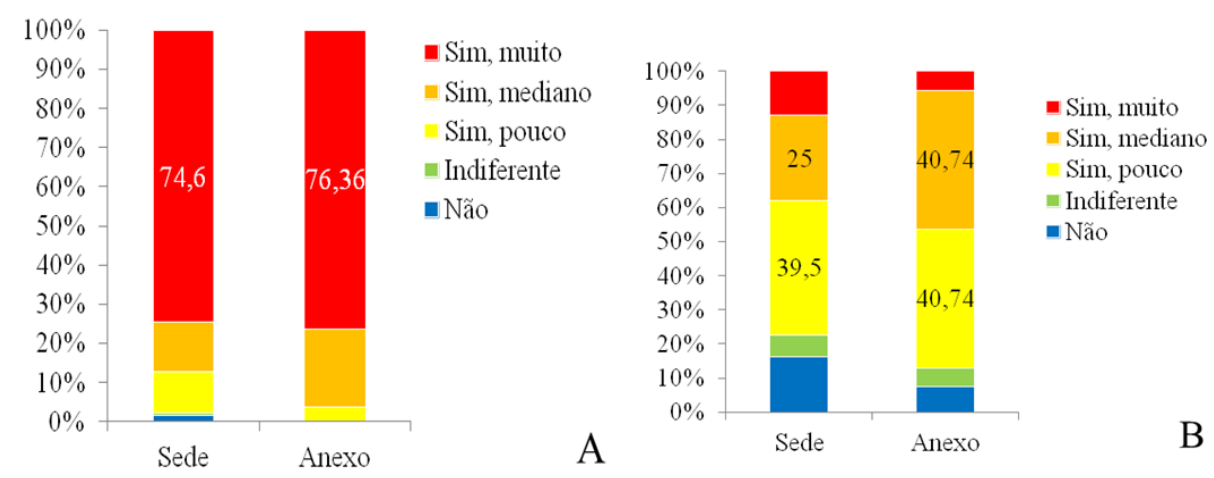

Figura 3: Respostas dos alunos quando questionados sobre se eles consideram que as ações do ser humano interferem na preservação do bioma (A) bem como se eles acreditam que a escola tem contribuído para a conservação do bioma (B).

Fonte: Dados da pesquisa (2020).

Quando os estudantes foram indagados se a escola tem contribuído para a conservação do bioma (Figura 3B), as respostas dos alunos foram principalmente "sim, pouco" (39,5\% sede / 40,74\% anexo) e "sim, mediano" (25\% sede / 40,74\% anexo). Através desses dados, podemos aferir que os alunos consideram que a escola poderia atuar de forma mais ativa frente às questões ambientais presentes no bioma, e que a mesma raramente dispõe de projetos para auxiliar na conservação, não propiciando, deste modo, aos estudantes, o processo de construção da identidade da cultura semiárida.

Destarte, a escola deveria dispor de um currículo que vise à contextualização do ensino com as características locais, potencialidades e limitações inerentes a esta região, e que, sobretudo fortaleça o sentimento de pertencimento deste povo (LIMA, 2006).

Em seguida, questionamos os alunos sobre a intensidade dos problemas ambientais vivenciados na região em que residem.

Os estudantes demonstram claramente suas percepções sobre as questões ambientais mais recorrentes na sua região, bem como a gravidade das mesmas. Embora as duas unidades escolares ressaltem as queimadas como um dos problemas mais graves, pode-se verificar que dois dos impactos mencionados, foram diferentes para alunos oriundos da zona urbana e zona rural: os estudantes da sede deram maior ênfase à poluição da água e o lixo, respectivamente, e os alunos do anexo apresentaram maior relevância para os agrotóxicos e as queimadas (Figura 4). A princípio, notamos que os estudantes reconhecem os problemas, a partir de realidades distintas. 

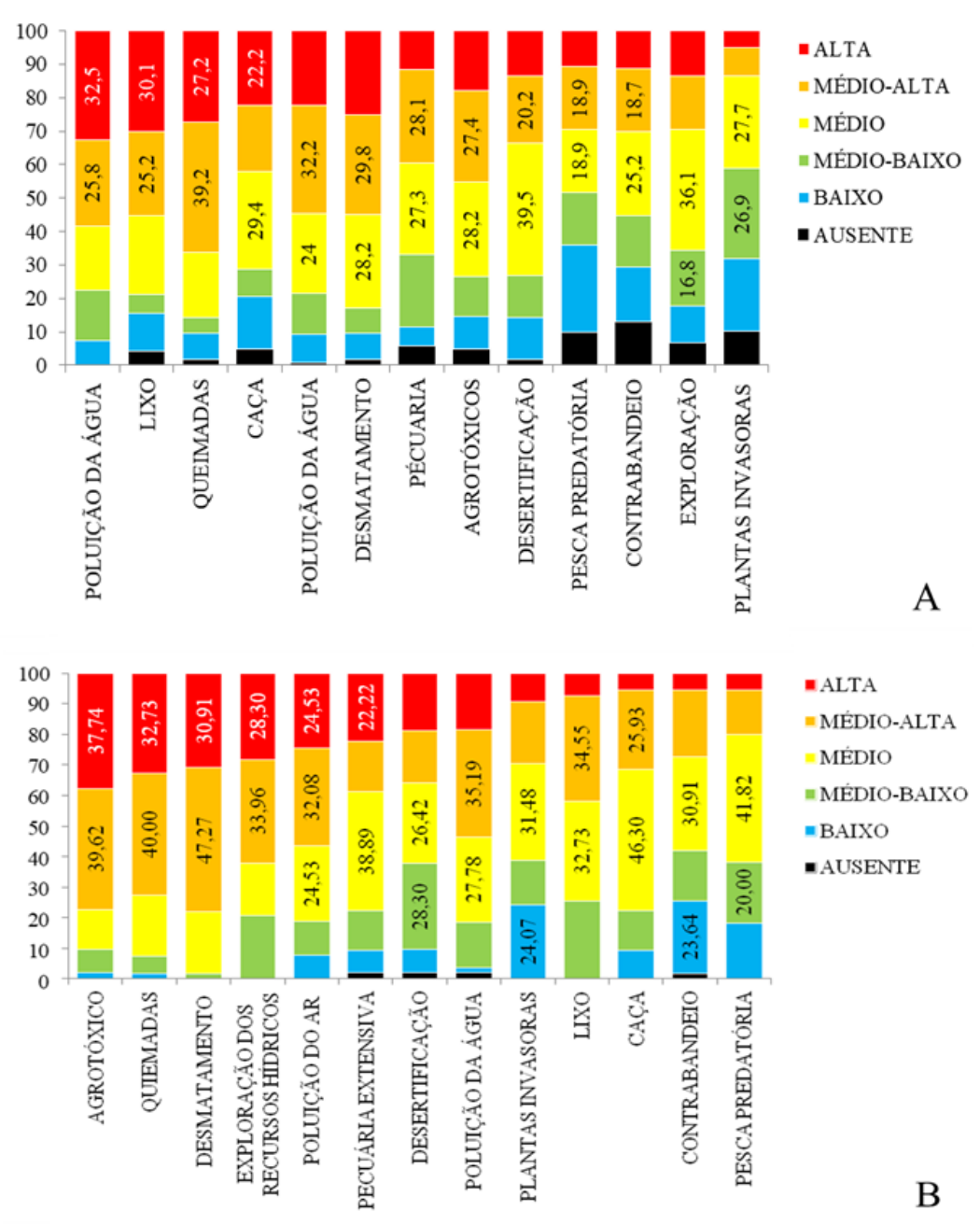

Figura 4: Respostas dos alunos quando questionados sobre a intensidade dos problemas ambientais na sua região $(A)$ sede e $(B)$ anexo. Os valores em destaque foram os mais representativos para cada uma das categorias avaliadas.

Fonte: Dados da pesquisa (2020).

Ainda sobre os apontamentos, os alunos da sede citaram impactos referentes ao lixo e suas implicações na vida urbana, destacando a necessidade de políticas públicas com foco na gestão de resíduos urbanos, demanda surgida com a globalização e o aumento das demandas socioeconômicas. Embora, a cidade onde a pesquisa foi desenvolvida seja de pequeno porte, os discentes citam a questão dos resíduos sólidos como um problema que merece cuidado e atenção por parte de todos, população e autoridades públicas.

Neste sentido, no Brasil a maioria do lixo produzido é descartado de forma incorreta nos chamados lixões. Esses por sua vez, geram sérios problemas ao meio ambiente, à medida que degradam o solo e seus resíduos vão atingindo o lençol freático, contaminando a água, e impossibilitando a utilização da mesma pela população (MMA, 2016). 
Entretanto, para alunos de zona rural, que vivem em sua maioria da agropecuária de subsistência, os impactos em sua maioria dizem respeito às atividades agrícolas. A utilização de agrotóxicos em larga escala pelos produtores rurais, tem causado sérios impactos ao meio ambiente, com a contaminação do solo, nascentes, refletindo diretamente na saúde da população (VEIGA, 2007).

As queimadas foram citadas por ambos os grupos de estudantes. $O$ ecossistema tem sofrido com as queimadas, especialmente pela poluição ambiental que atinge também a saúde humana, ocasionando doenças respiratórias (FERNANDES; GUEDES; PIRES, 2008).

De forma a complementar a compreensão sobre a intensidade dos problemas ambientais da Caatinga, foi solicitado que os estudantes sugerissem as problemáticas que necessitam de mais esforços para serem solucionadas. A partir disso, as respostas foram assim categorizadas: 1 - queimadas $(17,35 \%$ do total de alunos); 2 - desmatamento (17,04\%); 3 - aspectos sobre o lixo $(14,9 \%) ; 4$ - poluição (8,3\%); 5 - fiscalização $(7,1 \%) ; 6$ - medidas de sensibilização (6,9\%); 7 - agrotóxicos $(5,35 \%) ; 8$ - preservação e cuidados com o meio ambiente $(5,14 \%) ; 9$ - medidas do poder público $(4,23 \%) ; 10$ recursos hídricos $(3,17 \%) ; 11$ - caça $(2,85 \%) ; 12$ - contrabandeio (1\%); 13 pesca predatória $(0,53 \%)$.

A partir destes dados, percebemos a diversidade de problemas ambientais que interferem na vida dos estudantes. No geral, estes denotam a necessidade de uma mudança de postura na relação do homem com a natureza. Observa-se que é preciso reacender o sentimento de pertencimento dos seres humanos pela natureza e a identidade de que somos natureza (SAUVÉ, 2005).

Assim, os estudantes citaram diferentes medidas mitigadoras, destacando a coleta seletiva e a reciclagem do lixo. Neste sentido, a coleta seletiva visa diminuir a acumulação de resíduos e potencializar a reutilização dos mesmos (RIBEIRO, CARMO, 2000). Os estudantes ainda ressaltaram a necessidade de intervenção do poder público através de campanhas de sensibilização da sociedade e fiscalização.

Embora o poder público reconheça a atuação das entidades ambientais, este não disponibiliza de recursos que fomentem a ação efetiva das mesmas (PAIM; NOJOSA, 2013). Além disso, diante da necessidade de mudança nas relações socioambientais, a Educação Ambiental, tem se destacado, por se caracterizar como uma alternativa de sensibilização da sociedade, buscando a construção de uma cidadania ambiental (JACOBI, 2003).

Ainda no contexto de problemas ambientais, foi indagado aos alunos como suas vidas são impactadas por estes problemas. Como resposta obtevese as seguintes categorias: 1 - efeitos a saúde (55,4\% para todos os alunos); 2 - citam o problema sem citar a consequência (41,45\%); 3 - problemas na 
produtividade agrícola (3,8\%); 4 - não afetam a qualidade de vida (2,5\%); os percentuais ultrapassam os $100 \%$ (cem por cento) devido a exclusão da média entre os grupos de alunos. As categorias 4 e 5 não obtiveram representatividade para os alunos do anexo.

Assim sendo, é possível identificar que os estudantes enfatizam os danos à saúde decorrentes das queimadas, da poluição dos recursos hídricos e do uso de agrotóxicos. As doenças respiratórias tiveram destaque. Para Cançado et al. (2006), a poluição atmosférica afeta a saúde dos seres vivos, especialmente quando esta é decorrente da queima de combustíveis fósseis, ocasionando problemas respiratórios. Os agroquímicos, por sua vez, podem desencadear reações adversas à saúde humana, dependendo do tipo e frequência de contato (MARTINS et al., 2012).

Questionamos os alunos sobre quais ações são desenvolvidas na escola que contribuem para a conservação do bioma. As respostas foram categorizadas em dois grupos principais: 1 - ações educativas $(57,15 \%)$; e, 2 ações práticas de Educação Ambiental (28,35\%). No primeiro grupo estão as ações mais teóricas como feiras de ciências, palestras e campanhas formais de Educação Ambiental. No segundo grupo estão as ações mais práticas da Educação Ambiental, como passeatas para recolhimento de lixo, plantar árvores, entre outras. Além destas uma terceira categoria foi indicada quando o estudante não tinha participado (ou não lembrava) de nenhuma ação (14,5\%).

Através dos dados, as atividades que mais se destacaram entre todos os estudantes foram as voltadas à sensibilização e informação dos estudantes. Neste sentido, espera-se que a escola direcione e oriente os alunos para a construção de atitudes que visem a formação de cidadãos comprometidos com as questões socioambientais (AZEVEDO et al., 2012). Além disso, é necessário pensar em políticas públicas que visem uma pedagogia ambiental e fortaleça as escolas do semiárido, pois estas são relevantes no processo de formação sociocultural (ABÍLIO; FLORENTINO, 2016).

\section{Desenvolvimento Sustentável e Convivência com o Semiárido}

Uma vez que investigamos sobre os conhecimentos e vivências dos estudantes sobre aspectos gerais e relacionados à conservação da Caatinga, é necessário compreender também os conhecimentos e práticas voltadas para 0 desenvolvimento sustentável e a convivência com o semiárido. Assim, indagamos aos estudantes sobre suas percepções a respeito do desenvolvimento sustentável. Em resposta, 41,7\% dos estudantes da sede e $80 \%$ dos alunos do anexo afirmaram que "sim", conhecem algo sobre desenvolvimento sustentável; os demais alunos responderam "não". Aos que já tinham algum conhecimento sobre o assunto, foi solicitado que escrevessem o que compreendiam sobre o termo em questão. As respostas foram assim categorizadas: 1 - atividades que mudam a postura da sociedade em relação aos resíduos sólidos (50,3\% para todos os alunos); 2 - atividades que 
minimizem os impactos ambientais (47,9\%); 3 - atividades de subsistência $(21,35 \%) ; 4$ - associação com a utilização de produtos naturais $(10,5 \%)$; tal categoria é referente apenas aos alunos do anexo.

Os estudantes da sede, em sua maioria, relacionaram o termo desenvolvimento sustentável ao meio ambiente e à sustentabilidade, citando de forma discreta atividades com lucratividade. Por outro lado, os alunos do anexo associaram aos aspectos sobre o meio ambiente e a subsistência da população; neste grupo de alunos ainda merece destaque a categoria 4, em que o termo desenvolvimento sustentável foi associado à utilização de produtos naturais. Merece importância o contato dos alunos do anexo com a natureza, certamente por necessitarem desta para a sua sobrevivência. Para Sachs (2000) o estabelecimento de um desenvolvimento sustentável ocorre através de estratégias que promovam a conservação da biodiversidade para as populações que necessitam dos benefícios da natureza.

Ainda nessa perspectiva, foi solicitado aos estudantes que citassem até duas práticas no seu cotidiano que considerassem positivas para a convivência com o semiárido, e em seguida duas práticas negativas, na mesma concepção.

Embora se tenha solicitado que os estudantes escrevessem até duas práticas, observou-se que $33,02 \%$ e $3,85 \%$ dos alunos da sede e anexo, respectivamente, responderam apenas uma resposta. Sendo que, 57,15\% (sede) e 2,2\% (anexo) deixaram a questão em branco. Assim, obtivemos 82 e 51 respostas que indicam práticas citadas como positivas pela sede e anexo, respectivamente. Em relação à questão sobre práticas que causam impactos negativos ao ambiente, $38,1 \%$ e $2,75 \%$ dos estudantes da sede e do anexo, respectivamente, responderam apenas uma prática. $\mathrm{E} 57,15 \%$ dos alunos da sede e $1,65 \%$ do anexo deixaram a questão em branco. Ao todo foram contabilizadas 82 e 52 respostas que indicam práticas para a sede e anexo, respectivamente.

A partir destas respostas foram realizadas as análises de Bardin, cujas porcentagens para cada categoria estipulada estão expostas nos Quadros 1 (sede) e 2 (anexo).

De forma geral, percebemos que a prioridade para os alunos é evitar o acúmulo de lixo, reconhecendo a problemática da poluição ambiental em sua dimensão mais ampla. No trabalho de Manica e Johann (2019), os estudantes do ensino médio também mostraram preocupação com a destinação final do lixo, especialmente sobre o tratamento dos resíduos sólidos domésticos. Também concordamos com os autores do referido trabalho quando estes citam sobre a importância de trabalhos de Educação Ambiental como forma de conscientizar a população em relação à redução e reciclagem de resíduos sólidos. 
Quadro 1: Resposta dos alunos da sede quando questionados a respeito das práticas realizadas por eles no cotidiano que são boas para a convivência com semiárido, bem como as práticas realizadas que causam danos ao meio ambiente.

\begin{tabular}{|c|l|l|}
\hline Práticas de boa convivência com o semiárido & \multicolumn{2}{|c|}{ Práticas que causam danos ao semiárido } \\
\hline - Preservar a natureza $(24,4 \%)$ & - Poluição da água/ar $(27,4 \%)$ \\
- Evitar jogar lixo $(25,2 \%)$ & - Produzir lixo $(24,2 \%)$ \\
- Não poluir o meio ambiente $(16 \%)$ & - Fazer queimadas $(18,5 \%)$ \\
- Não desperdiçar água $(12,6 \%)$ & - Desmatar $(12,9 \%)$ \\
- Não desmatar $(6,7 \%)$ & - Utilizar veículos $(7,3 \%)$ \\
- Reciclagem $(7,6 \%)$ & - Caçar para contrabandear $(5,6 \%)$ \\
- Evitar queimadas $(4,2 \%)$ & - Desperdiçar água $(3,2 \%)$ \\
- Não utilizar agrotóxicos $(1,7 \%)$ & - Utilizar agrotóxicos $(0,8 \%)$ \\
- Evitar a caça $(1,7 \%)$ & \\
\hline
\end{tabular}

Nota: entre parêntese, ao lado de cada categoria, está o percentual de respostas que cada uma delas obteve pela análise de Bardin. Fonte: Dados da pesquisa (2020).

Quadro 2: Resposta dos alunos do anexo quando questionados a respeito das práticas realizadas por eles no cotidiano que são boas para a convivência com semiárido, bem como as práticas realizadas que causam danos ao meio ambiente.

\begin{tabular}{|c|l|l|}
\hline Práticas de boa convivência com o semiárido & Práticas que causam danos ao semiárido \\
\hline - Não desperdiçar água $(20,2 \%)$ & - Fazer queimadas $(44,2 \%)$ \\
- Preservar a natureza $(18,1 \%)$ & - Desmatar $(18,9 \%)$ \\
- Plantar mais árvores $(13,8 \%)$ & - Utilizar agrotóxicos $(15,8 \%)$ \\
- Não jogar lixo em local errado (14,9\%) & - Produzir lixo em excesso $(6,3 \%)$ \\
- Reciclar/reutilizar $(10,6 \%)$ & - Poluição $(4,2 \%)$ \\
- Não desmatar $(8,5 \%)$ & - Desperdício de recursos naturais \\
- Evitar queimadas $(6,4 \%)$ & - Pecuária $(3,2 \%)$ \\
- Não poluir $(6,4 \%)$ & - Caçar $(3,2 \%)$ \\
- Evitar pecuária extensiva $(1,1 \%)$ & - Utilizar automóveis $(1,1 \%)$ \\
\hline
\end{tabular}

Nota: Entre parêntese, ao lado de cada categoria, está o percentual de respostas que cada uma delas obteve pela análise de Bardin. Fonte: Dados da pesquisa (2020).

Os alunos da zona rural destacaram com maior frequência as práticas de economia hídrica, preservação da natureza e destinação correta dos resíduos, como as mais realizadas em seu cotidiano. Devido à escassez hídrica no semiárido nordestino, os moradores desta região aprendem desde cedo a sobreviver economizando a pouca água disponível, principalmente em áreas que não possuem sistemas de abastecimento, e por vezes, os moradores necessitam andar quilômetros para adquirir água, tornando esse recurso ainda mais significativo para estas pessoas. Campos (2002) ressalta a gravidade do problema hídrico no Nordeste, principalmente em áreas rurais, tendo em vista que durante boa parte do ano a população precisa do atendimento de carros-pipas para a sobrevivência.

Ainda em relação às práticas realizadas pelos alunos com foco na convivência com o semiárido, pedimos que relatassem dentre as suas práticas diárias, as que causavam dano ao ambiente. Quanto a este questionamento, as atividades mais citadas pelos estudantes da sede e que atingem o bioma Caatinga foram: poluição da água e do ar, produção de lixo, e queimadas. 
Curiosamente os impactos mais relatados por eles que causam algum malefício para as suas vidas, são também os que eles mais praticam. Deste modo, percebemos o quanto é necessária a mudança de paradigma, na tentativa de construir uma cultura de convivência. Para compreender melhor essa relação do homem com o meio ambiente na Caatinga, é preciso substituir o paradigma de combate à seca por uma alternativa mais viável na perspectiva sustentável: a convivência com o semiárido (SCHISTEK, 2013).

Dentre as categorias mencionadas pelos alunos do anexo, percebemos que as ações que estes mais desempenham rotineiramente e que causam danos à Caatinga, são as queimadas, o desmatamento e a utilização de agrotóxicos. As respostas dos alunos em sua maioria relacionam-se com as ações advindas das práticas agrícolas, com a finalidade de tornar a terra mais fértil para a plantação.

Quando reconhecemos o contexto em que os estudantes estão inseridos, percebemos a afinidade com as respostas aqui dadas. O semiárido nordestino é um dos mais populosos do mundo e boa parte desta população vive em áreas rurais. Para sobreviver os nordestinos retiram da natureza os insumos que necessitam para a produção; contudo, tais atividades extrativistas têm potencialmente atingido a conservação do bioma Caatinga (SAMPAIO; ARAÚJO; SAMPAIO, 2005). Entretanto, faz-se necessário diferenciar o extrativismo praticado por famílias de agricultores tradicionais, do realizado por pessoas que têm 0 intuito de garantir lucratividade. Os primeiros causam maiores danos ao ambiente (CARDEL et. al, 2014).

Ao serem questionados se o desenvolvimento sustentável auxilia na manutenção do bioma, os alunos da sede e do anexo responderam, predominantemente, "sim, muito" (Figura 5A).
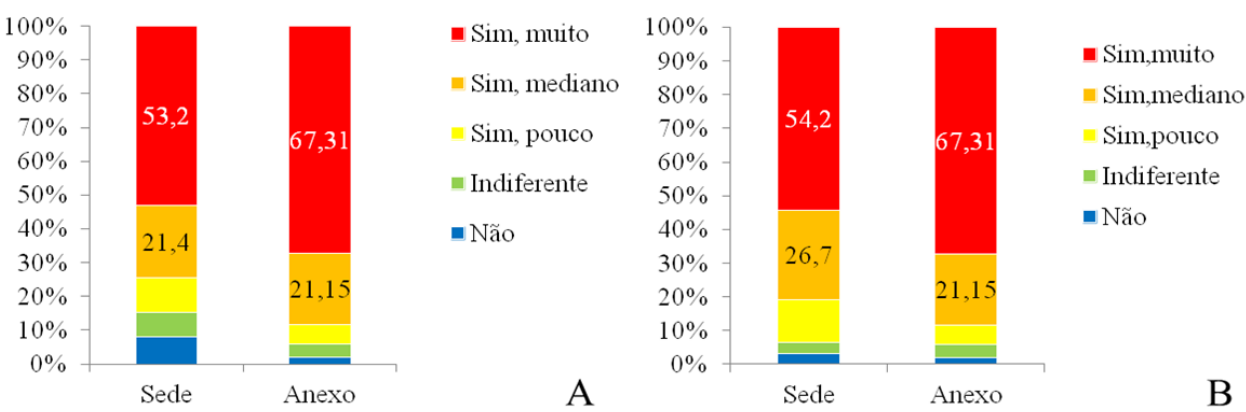

Figura 5: Respostas dos alunos quando indagados se eles consideram importante o desenvolvimento de forma sustentável para a manutenção do bioma Caatinga $(A)$ e se os mesmos consideram que o desenvolvimento sustentável contribui para a vida de moradores de áreas rurais (se você morar na zona rural) ou urbanas (se você morar em zona urbana (B).

Fonte: Dados da pesquisa (2020). 
A partir dos resultados é possível perceber que os alunos consideram o desenvolvimento sustentável importante, numa demonstração clara que eles se sensibilizam com a situação dos recursos naturais e com a relevância de práticas sustentáveis na Caatinga, possibilitando a permanência dos mesmos na região. Contudo, o desenvolvimento sustentável vai além do conceito de produzir bens e garantir a permanência do recurso; na verdade, busca-se uma modificação do estilo de vida das pessoas, na perspectiva de quebra de paradigmas de dominação na relação homem-natureza (GUSMÃO, 2009).

Ao serem indagados se o desenvolvimento sustentável contribui para a vida de moradores de áreas urbanas e rurais, a resposta dos alunos de ambas as seções dessa unidade escolar também foi, predominantemente, "sim, muito" (Figura 5B). Isso demonstra que os estudantes acreditam que 0 desenvolvimento sustentável é possível, independentemente da região, e que este fortalece a relação entre o homem e a natureza, garantindo a subsistência das pessoas, sem esquecer da preservação e conservação do ambiente.

O desenvolvimento sustentável busca atuar em várias esferas, como a econômica, social e ambiental, buscando novas práticas de manejo que otimizem a relação dos seres humanos com a natureza e assim proporcionar uma fonte de renda para o produtor rural (MENEZES; SOUZA, 2011). Nesse contexto, o desenvolvimento sustentável é uma proposta de vida que aponta para uma sustentabilidade planetária, garantindo o bem-estar da população, a partir da preservação dos recursos naturais do planeta (GADOTTI, 2012).

\section{Considerações Finais}

Por meio desta pesquisa é possível perceber com nitidez a diferença entre os dados coletados e analisados nas duas unidades da escola em questão. Os sujeitos da pesquisa possuem conhecimentos relevantes sobre 0 bioma, especialmente referente aos aspectos físicos. Entretanto, percebemos que os alunos da sede destacaram maior índice de plantas e animais no que se refere à diversidade destes na Caatinga, além de perceberem as consequências da ação antrópica no bioma de diferentes formas.

Os alunos da sede destacam problemas relacionados aos resíduos sólidos, enquanto os alunos do anexo enfatizaram os aspectos relacionados às práticas agrícolas, identificando estas como responsáveis pela condição atual dos recursos naturais da região. Além disso, observamos que os estudantes do anexo compreendem de forma mais concreta e aplicável sobre o que representa o desenvolvimento sustentável e o contexto ambiental da região, quando comparados aos estudantes da área urbana. Contudo, observa-se uma dicotomia, pois, ao tempo em que os estudantes compreendem os efeitos desta interferência e sabem das possíveis formas de mitigar os impactos ambientais, estes, por sua vez, não efetuam medidas / condutas necessárias para solucionar a problemática. 
Por fim, percebemos a urgente necessidade da disseminação de conhecimentos sobre a Caatinga e de uma mudança efetiva de paradigma da relação homem-natureza. Logo, é fundamental a construção de momentos de sensibilização destes estudantes e, certamente da comunidade local, para as questões ambientais, na perspectiva de ações que possam verdadeiramente contribuir para a redução dos impactos neste bioma.

Diante disso, esperamos ansiosamente por mudanças efetivas e pugnamos por uma educação para o semiárido que possa atuar de maneira formal e informal, desenvolvendo uma proposta pedagógica contextualizada e que contribua para a manutenção das riquezas naturais e para a vivência na região.

\section{Referências}

ABÍLIO, F. J.; FLORENTINO, H. S. Elos da Educação Ambiental Sustentável: caminhos para uma pedagogia contextualizada no seminário Paraibano. Revista Temas em Educação, v. 25, n. especial, p. 172-193, 2016.

ALVES, L. I. F.; SILVA, M. M. P.; VASCONCELOS, K. J.C. Visão de comunidades rurais em Juazeirinho/PB referente à extinção da biodiversidade da caatinga. Revista Caatinga, v. 22, n. 1, p.180-186, 2009.

ALVES, R. R. N.; GONÇALVES, M. B. R.; VIEIRA, W. L. S. Caça, uso e conservação de vertebrados no semiárido brasileiro. Tropical Conservation Science, v. 5, n. 3, p. 394-416, 2012.

ARAÚJO, G. G. L.; HOLANDA, E. V. J.; KIIL, L. H. P.; CAMPANHA, M. M.; GOMES, T. O. Potencial forrageiro da caatinga na comunidade de Testa Branca, Uauá-BA. Embrapa Semiárido-Fôlder/Folheto/Cartilha (INFOTECAE), Petrolina, 2008, p.15.

ARROYO, M. G.; CALDART, R. S.; MOLINA, M. C. (Orgs.). Por uma educação do campo. $5^{\mathrm{a}}$ ed. Petrópolis, Rio de Janeiro: Vozes, 2011.

AZEVEDO, A. K.; SANTOS, M. C. D.; PIMENTA, H. C. D.; SILVA, V. P. A Educação Ambiental e sua influência nas atitudes de alunos de uma escola de ensino fundamental de Natal/RN. Engenharia Ambiental: Pesquisa e Tecnologia, v. 9, n. 4, p. 039-065, 2012.

BARDIN, L. Análise de Conteúdo. Tradução: Luís Augusto Pinheiro. São Paulo: Edições 70, 2016.

CAMARGO, A. L. B. Desenvolvimento sustentável: Dimensões e desafios. Campinas, SP: Papirus, 2003.

CAMARGO, B. V.; JUSTO, A. M. Iramuteq: um software gratuito para análise de dados textuais. Temas em Psicologia, v. 21, n. 2, p. 513-518, 2013.

CAMPOS, J. N. B. Água, sociedade e natureza Desenvolvimento científico e gestão de águas. In: HOFMEISTER, W.; MACEDO, M.; KÜSTER, A.; 
HERMANNS, K.; ARAÚJO, M.; JUNIOR, A. Água e desenvolvimento sustentável no Semi-Árido. Fortaleza: Ed. Fundação Konrad Adenauer, 2002. p. 19-34.

CANÇADO, J. E. D.; BRAGA, A.; PEREIRA, L. A. A.; ARBEX, M. A.; SALDIVA, P. H. N.; SANTOS, U. P. Repercussões clínicas da exposição à poluição atmosférica. Jornal Brasileiro de Pneumologia, v. 32, supl. 2, p. 5-11, 2006.

CARDEL, L. M. P. S.; OLIVEIRA, M. A. J.; GUEDES, L. S.; SANTANA, F. A. O uso das plantas e o saber tradicional em três comunidades Ribeirinhas do Rio São Francisco. Revista Cadernos de Ciências Sociais da UFRPE, v. 1, n. 1, p. 128-151, 2014.

CAVALCANTI, N. de B.; RESENDE, G. M. Plantas nativas da caatinga utilizadas pelos pequenos agricultores para alimentação dos animais na seca. In: III Congresso Nordestino de Produção Animal, 3. 2004, Campina Grande. [Anais...] Campina Grande: CNPA, 2004. Disponível em <https://ainfo.cnptia. embrapa.br/digital/bitstream/CPATSA/30291/1/OPB619.pdf> Acesso em 18 dez. 2020.

DUARTE, R.G.; BASTOS, A.T.; SENA, A. P.; OLIVEIRA, F.C. Educação Ambiental na convivência com o semiárido: Ações desenvolvidas pela Secretaria de Educação do Estado do Ceará. Revista de Gestão Ambiental e Sustentabilidade, v. 4, n. 1, p. 17-29, 2015.

EVANGELISTA, A. R. S. O processo de desmatamento do bioma caatinga: riscos e vulnerabilidades socioambientais no território de identidade do sisal, Bahia. Revista Geográfica de América Central, v. 2, n 47, especial, p. 1-13, 2011.

FERNANDES, A. P. A.; GUEDES, B. B.; PIRES, L. F. G. Efeitos sócioambientais causados pela queimada da cana-de-açúcar no município de Piracicaba. Revista Ciências do Ambiente On-Line, v. 4, n. 2, p. 1-6, 2008.

GADOTTI, M. Educar para a sustentabilidade: uma contribuição à década da educação para o desenvolvimento sustentável. 2 ed. São Paulo: Editora e Livraria Instituto Paulo Freire, 2012.

GIL, A.C. Como elaborar projetos de pesquisa. 5. ed. São Paulo: Atlas, 2010.

MANICA, E. J.; JOHANN, L. Avaliação do conhecimento de alunos do ensino médio sobre o destino dos resíduos sólidos domésticos. Revista Brasileira de Educação Ambiental, v. 14, n. 4, p. 74-86, 2019.

GRAY, D. E. Pesquisa no mundo real. 2 ed. São Paulo: Artmed, 2012.

GUSMÃO, P. P. Sistemas municipais de governo e desenvolvimento sustentável na região do semiárido brasileiro. Planejamento e Políticas Públicas, n. 14, p. 158-236, 2009.

JACOBI, P. Educação Ambiental, cidadania e sustentabilidade. Cadernos de pesquisa, v. 118, n. 3, p. 189-205, 2003. 
LIMA, E. S. Educação contextualizada no semiárido: construindo caminhos para formação de sujeitos críticos e autônomos. Monografia. Curso de especialização em Docência do Ensino Superior da Faculdade Santo Agostinho-FSA, Teresina/PI. 2006. 88f.

MARENGO, J. A.; ALVES, L. M.; BESERRA, E. A.; LACERDA, F. F. Variabilidade e mudanças climáticas no semiárido brasileiro. Recursos hídricos em regiões áridas e semiáridas: Instituto Nacional do SemiáridoINSA, Campina Grande, p. 384-422, 2011.

MARTINS, M. K. S.; CERQUEIRA, G. S.; SAMPAIO, A. M. A; LOPES, A. A; FREITAS, R. M. Exposição Ocupacional aos Agrotóxicos: Um Estudo Transversal. RevInter Revista Intertox de Toxicologia, Risco Ambiental e Sociedade, v. 5, n. 3, p. 6-27, 2012.

MENEZES, R.; SOUZA, B. I. Manejo Sustentável dos recursos naturais em uma comunidade rural do semi-árido nordestino. Cadernos do Logepa, v. 6, n. 1, p. 41-57, 2011.

MORO, M. F., SOUZA, V. C.; OLIVEIRA-FILHO, A. T.; QUEIROZ, L. P.; FRAGA, C. N.; RODAL, M. J. N.; ARAÚJO, F. S.; MARTINS, F. R. Alienígenas na sala: o que fazer com espécies exóticas em trabalhos de taxonomia, florística e fitossociologia? Acta Botanica Brasilica, v. 26, n. 4, p. 991-999. 2012.

NUNES, L. A. P. L.; FILHO, J. A. A.; JUNIOR, E. V. H.; MENEZES, R. I. Q. Impacto da queimada e de enleiramento de resíduos orgânicos em atributos biológicos de solo sob caatinga no semi-árido nordestino. Revista Caatinga, v. 22, n. 1, p. 131-140, 2009.

OLIVEIRA, J. A.; GONÇALVES, P. R.; BONVICINO, C. R. Mamíferos da caatinga. In: LEAL, I. R., TABARELLI, M, SILVA, J. M. C. (Eds). Ecologia e conservação da Caatinga. Recife: Ed. Universitária da UFPE, 2003. p. 275302.

OLMOS, F.; SILVA, W. A. G.; ALBANO, C. G. Aves em oito áreas de Caatinga no sul do Ceará e oeste de Pernambuco, nordeste do Brasil: composição, riqueza e similaridade. Papéis Avulsos de Zoologia, v. 45, n. 14, p. 179-199, 2005.

PAIM, I. M.; NOJOSA, D. M. B. A formação em Educação Ambiental: limites e possibilidades. In: LIMA, I.B.(Org.). Didática, Educação Ambiental e ensino de ciências e matemática: múltiplos olhares. Fortaleza: EDUECE, 2013. Cap. 4 p. 213-229.

PIMENTEL, J. V. F.; GUERRA, H. O. C. Semiárido, caatinga e legislação ambiental. Prim@ Facie, v. 8, n. 14, p. 104-126, 2009.

PRODANOV, C. C.; FREITAS, E. C. Metodologia do trabalho científico: métodos e técnicas da pesquisa e do trabalho. 2. Ed. - Novo Hamburgo: Feevale, 2013. 
OLIVEIRA, F. G.; QUEIROZ, L. P. Prosopis in Flora do Brasil 2020 em construção. Jardim Botânico do Rio de Janeiro. Disponível em $<$ http://floradobrasil.jbri.gov.br/reflora/floradobrasil/FB18990>. Acesso em 04 jan. 2021

RIBEIRO, T. F.; CARMO, S. L. Coleta seletiva de lixo domiciliar-estudo de casos. Caminhos de geografia, v. 2, n. 2, p. 50-69, 2000.

SACHS, I. Caminhos para o desenvolvimento sustentável. 2 ed. Rio de Janeiro: Garamond, 2000.

SALATINO, A.; BUCKERIDGE, M. "Mas de que te serve saber botânica? Estudos avançados, v. 30, n. 87, p. 177-196, 2016.

SAMPAIO, E. V. S. B.; ARAÚJO, M. S. B.; SAMPAIO, Y. S. B. Impactos ambientais da agricultura no processo de desertificação no Nordeste do Brasil. Revista de Geografia, v. 22, n. 1, p. 90-112, 2005.

SAMPAIO, E. V. S. B.; COSTA, T. L. Estoques e Fluxos de Carbono no Semiárido Nordestino: Estimativas Preliminares. Revista Brasileira de Geografia Física, v. 4, n. 6, p. 1275-1291, 2012.

SAMPIERI, R. H.; COLLADO, C. F.; LUCIO, M. L. P. B. Metodologia da pesquisa. 5 ed. Porto Alegre: Penso, 2013.

SAUVÉ, L. Educação Ambiental: possibilidades e limitações. Educação e pesquisa, v. 31, n. 2, p. 317-322, 2005.

SCHISTEK, H. O semi-árido brasileiro: uma região mal compreendida. In: CONTI, I. L.; SCROEDER, E. O. Convivência com o semiárido brasileiro. Brasília: Ed. IABS, 2013. Cap. 2 p.41-53.

VEIGA, M. M. Agrotóxicos: eficiência econômica e injustiça socioambiental. Ciência \& Saúde Coletiva, v. 12, n. 1, p. 145-152, 2007.

VELLOSO, A. L.; SAMPAIO, E. V. S. B.; PAREYN, F. G. C. Ecorregiões: Propostas para o bioma caatinga. Recife: Associação Plantas do Nordeste; Instituto de Conservação Ambiental The Nature Conservancy do Brasil, 2002. Disponível em <https://issuu.com/acaatinga/docs/ecorregi es- propostas para o bioma caatinga> Acesso em 14 dez. 2020.

ZANELLA, F. C. V.; MARTINS, C. F. Abelhas da Caatinga: biogeografia, ecologia e conservação. In: LEAL, I. R.; TABARELLI, M.; SILVA, J. M. C.(Eds). Ecologia e conservação da Caatinga. Recife: Ed. Universitária da UFPE, 2003. p. $75-134$.

ZILLER, S. R. Os processos de degradação ambiental originados por plantas exóticas invasoras. Ciência Hoje, v. 30, n. 178, p. 77-79, 2001.

RIBEIRO, E. M. S.; LIMA, R. L. F. A. Educação Ambiental na Caatinga: aprendendo 0 valor da biodiversidade e seus serviços ecossistêmicos no ensino escolar. Revista Brasileira de Educação Ambiental, v. 15, n. 6, p. 1-3, 2020. 